\title{
Beyond a Common Code: Cameroon Pidgin English - the Language of the Elite and the Masses
}

\author{
Rachel Ayuk Ojong Diba (Corresponding author) \\ Linguistics Department, Faculty of Arts, the University of Buea, Cameroon \\ Email: ashly4roda@yahoo.com
}

Received: $14 / 11 / 2020$

Accepted: 19/01/2021

Published: 01/03/2021

Volume: 2 Issue: 2

How to cite this paper: Ojong Diba, R. A. (2021). Beyond a Common Code: Cameroon Pidgin English - the Language of the Elite and the Masses. Journal of Critical Studies in Language and Literature, 2(2), 22-29

DOI: https://doi.org/10.46809/jcs1l.v2i2.55

Copyright (C 2020 by author(s) and Global Talent Academy Ltd. This work is licensed under the Creative Commons Attribution International License (CC BY 4.0).

http://creativecommons.org/licenses/by/4.0/

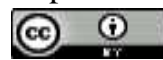

\begin{abstract}
The principal purpose of this paper is to underline the usefulness and efficacy of Cameroonian Pidgin English (CPE) in dealing with the intense multilingualism of Cameroonians in a rural enclave in Cameroon and in the Diaspora. CPE is a highly stigmatized but extensively used language of wider communication in Cameroon. Cameroon is second only to Papua New Guinea in terms of its multiplicity of languages for a relatively small population and the shunned CPE is the language that trudges through this multi-ethnicity, multiculturalism and multilingualism to not only provide a feeling of togetherness to Anglophone Cameroonians but to also allow them communicate efficiently and cordially. CPE was incipiently a language for the uneducated, this contribution shows that today CPE is not only the language of the common people; it is also the language of the Cameroonian elite. Using qualitative data - recordings of natural conversations from individuals in Lower Fungom and written conversation from online fora comprising Cameroonians of all walks of life, this contribution demonstrates that CPE is an emblematic language which Cameroonians use when communication would otherwise be impossible and still use it even when there is an option (though one-legged) of other languages. The paper demonstrates how multilingualism functions even in rural circles. It is also demonstrates the benefits of Pidgins and Creoles in linguistically diverse settings, which are relatively uncommon.
\end{abstract}

Keywords: Cameroonian Pidgin English, Multilingualism, Multiculturalism, Communication

\section{Introduction}

Cameroon Pidgin English (CPE) is the most widely spoken lingua franca in Cameroon. Aside CPE other lingua francas in Cameroon include Bassa, Ewondo and Fulfulde. Cameroon is one of the most linguistically fragmented countries in Africa (Chiatoh, 2014) with about 280 living languages (Ethnologue 2020), for an estimated population of 26,727,521 people (Worldometer, 2020). Worthy of note, it is second only to Papua New Guinea in terms of its multiplicity of languages for a relatively small population (Atechi, 2011). French and English have been the two official languages of the country since 1961; they enjoy overt prestige resulting from their statuses as the only two official language of the country. CPE however enjoys covert prestige bestowed on it by Cameroonians as a language of wider communication, social interaction and intimacy (Atechi, 2011). Neba, Atindogbe \& Fogwe, (2006) assert that CPE is present in five of the regions of Cameroon, although its impact is limited to the big cities of Douala and Yaounde, in the Littoral and Centre Regions, respectively. They maintain that in the North West and South West regions, it is the only lingua franca hence its pertinence to its speakers. 
Echu (2003) traces the origin of CPE far back to the $18^{\text {th }}$ century when English traders and missionaries first landed on the coast of West Africa. Communication was impossible, so CPE emerged in an attempt to facilitate effective communication in the area of trade and evangelization. After the abolition of slave trade at the beginning of the $19^{\text {th }}$ century, the language continued to expand all over the coastal region due to contact with freed slaves and missionaries. Then there was colonization; Achimbe (2007), sees pidgins in general as a second linguistics consequence of colonization after English and French. In his opinion, colonization brought with it a mixture of culture, languages and identities. Pidgins were thus further developed between colonizers and slaves especially on the plantations and with German soldiers (Todd 1990).

As far as its composition is concerned, CPE is an English-lexified language, equally composed of African languages. It is a Creole as Neba et al (2006) affirm that about five percent of Cameroonians are native speakers of the language, while about 70 percent of the population can speak it albeit as non-natives.

CPE is an indispensable tool to deal with multilingual and multicultural challenges in Cameroon as it is used across the board and it belongs to no particular ethnic group in Cameroon. As a result, its usage does not trigger any ethnic contention. Cameroonians have moved to other countries in Africa and overseas in search of a better lifestyle. Cameroon is already intensely linguistically and culturally diverse and some of these emigrated Cameroonians move into other countries adopting additional languages. In the midst of these distinctive linguistic repertoires, the ethnic-neutral CPE allows these emigrants to share a way of life that is linked to their culture and history. To them, CPE is a language that not only allows for smooth communication but also enshrines their commonality and a national personality; it unifies and identifies them as an entity.

In addition, in Lower Fungom, an entwined, rural, intensely linguistically diverse area in the North West region of Cameroon, CPE is an absolute necessity; it fulfills a dire communicative role. In Lower Fungom unlike in most urban centers, almost only the local languages of the area are used in daily interactions. As such, if a stranger or an individual from another village with a mutually unintelligible language joined a discussing group, the local language would be dropped in favour of CPE and this would be a signal for inclusion, it would signal a desire to communicate with the new interlocutor. Also, if individuals from Lower Fungom had to converse with people from different ethnicities - strangers of Lower Fungom, Standard English would most certainly not be an option; CPE would permit communication between these individuals.

The principal purpose of this paper is to underline the usefulness and efficacy of CPE in dealing with the intense multilingualism of Cameroonians in a rural enclave and in the diaspora. Since its inception, CPE has been a language that bridges a profound need for communication. In the $18^{\text {th }}$ century, it was between the indigenous people and foreign traders and missionaries. Today, it is between Cameroonians of diverse, distinct linguistic and cultural backgrounds. CPE is a language that arose as a result of the desperate need for communication among people who spoke mutually unintelligible languages, one which at its inception was spoken mostly by the uneducated. It is a language that has been brutally stigmatized as authorities all over the country attempted to ban it, referring to it with derogatory terms as 'broken English' and 'poor English'. Nevertheless, the language, like a seed thrown into a dumpster has continued to flourish and has now established itself as a major force to reckon with in the linguistic landscape of the country (Atechi, 2011). This language that used to be marginal has shown itself to be resilient, highly robust and most importantly incredibly expedient. This paper showcases CPE as a resource language in an intensely linguistically and ethnically diverse country.

\section{Methodology}

In order to gain a better insight into the communicative valour of CPE, this qualitative study went for both oral and written data. Both are appropriate for the objective of the study which is to shine a light on the communicative strong suit of CPE to Anglophone Cameroonians in two distinct groups - elite and masses or rural and urban. The data comprises recordings of spontaneous conversations obtained with the use of a video recorder, from individuals in Lower Fungom in 2020 and written chats from two online fora on Facebook obtained in 2018. Prolonged stays in Lower Fungom allowed for observation as an additional method of data gathering. For ethical purposes and as qualitative research would prescribe, the original names of participants in this research have been changed, the names in the paper are thus fictitious names provided by the author.

For the first group, data was obtained from in individuals in Lower Fungom. The data was obtained during a memorial service in Lower Fungom. I chose to explore conversations of groups in public spaces as they were made up of wide variety of individuals; those from distinct villages of Lower Fungom and also strangers. Such linguistically diverse groups will strongly highlight the need for CPE for effective communication.

Data from the online fora was chosen first of all because its participants are markedly different from those in Lower Fungom. They are more educated, sophisticated and reside in developed countries, in environments where CPE is nonexistent. Their deliberate preference of CPE alone in the diversity of the group will be apt to illustrate the communicative pertinence of CPE.

Based on the objectives of the paper, the discourse analysis method was used for data analysis. Conversations were examined in relation to their social context in order to gain understanding of participant's goals and motivations in the conversation.

These real-lives, spontaneous conversations would provide a more in-depth understanding of participants' emotions and motivation for using CPE. 


\section{CPE for Anglophone Cameroonians in the Diaspora}

Cameroon is indeed a Babbel with numerous unintelligible languages and two official languages which are not even the second best language to a vast majority. Anglophone Cameroonians have been using CPE over the years, even pre-school children especially in urban settings have a good mastery of CPE and only gain a mastery of English language later at school. According to Mba (2011), many children more often than not have pidgin instead of their maternal or paternal native language. This is because CPE is used in buying and selling, in churches and in homes. In fact, CPE is a Creole rather than a pidgin to a great number of Anglophone Cameroonians - 5\% according to Neba et al (2006). Be it as a Creole or as a Pidgin, the language is spoken by numerous Anglophone Cameroonians seamlessly, unlike the ex-colonial languages. After all, as Neba et al (2006) affirm, CPE has the structure of an African language, hence the predisposition.

CPE has gained grounds all over the national territory and Cameroonian immigrants have carried it along into their new host countries. In addition, non-Cameroonians, who have lived and worked in Cameroon for a number of years have also learnt this language and are using it with Cameroonians.

Two online fora were randomly selected for this study and data was collected based on conversations that happened in 2018. One of the fora is called Camerjokes and it is assessed through Facebook. It comprises mostly Cameroonians in Europe and America and two foreigners: a Swiss and a South African. The Swiss was married to a Cameroonian and the South African had worked in Cameroon for about five years. These two individuals since in contact with Cameroonians have learnt $\mathrm{CPE}$ and use it fluently. This forum serves the purpose of sharing vital information and jokes too; it is required that these jokes be shared only in CPE. Sometimes there is a blend of CPE and English, but most often, participants of the forum use only CPE. After all, in all honesty, humour is better expressed in CPE than in English. Using the English language for jokes would certainly slow down or completely impede the flow of some information, meta-information associated with jokes. CPE has been associated with a lack of formal education and primitiveness but worthy of note, none of these participants is uneducated; they all have admirable social statuses. The creator of the forum himself is a laureate from the Higher Teacher Training College, ENS Bambili, Cameroon and is currently a teacher in the UK. The other members include an independent businessman, registered state nurses, an interpreter at ASTI who used to live and work in the UK, a real estate broker who lives and works in Canada, a journalist at the CRTV, a lawyer in Douala, history lecturer at the university of Basel, Switzerland, nurse in the US, a Cameroonian with the US army, a medical doctor and a holder of a master's in public health, who lives and works in Bamenda.

Consider the excerpt below from Camerjokes (also known as CJ) illustrating the use of CPE by these Cameroonians in the diaspora. In this excerpt, a member of Camerjokes (Daniel) posted an image and as expected, other members of the group named and numbered from 1 to 6 (as participant 1-6) react to it. The original text is in CPE and it is in italics, the English translation follows it.

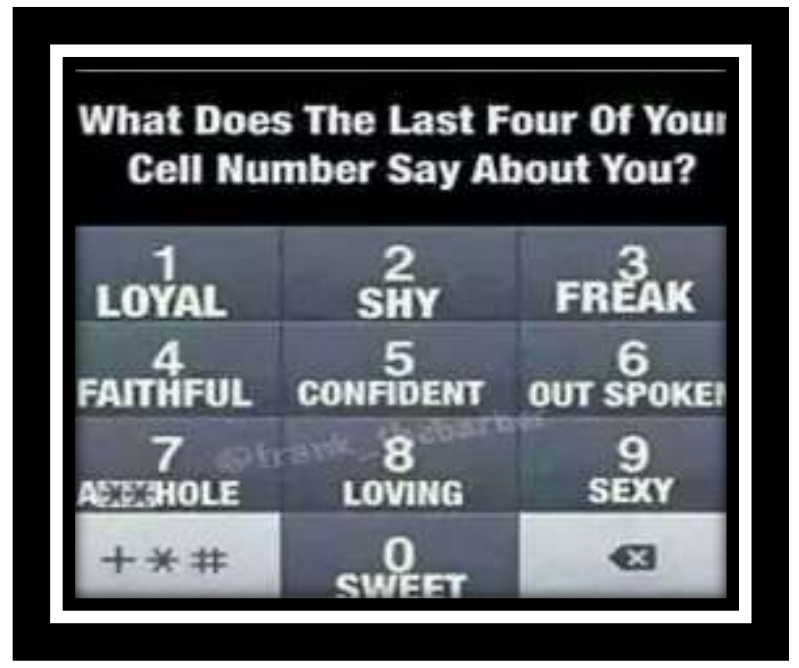

Image 1. Personalities in relation to phone digits

\section{Participant 1: Fred}

CPE: So na only me and Ivory get no 7 for the whole this CJ? Chei!!! And na so i di see plenty no 7 dem around. I go give example oh!!!!

English: So it is only Ivory and I whose phone numbers contains number 7? Chei!!! And I can See many numbers seven around. I will give examples oh!!

Participant 2:_Ashu

English: I plead the fifth

\section{Participant 3: Zui}

CPE: $\quad$ Danny i no get time. Cosh na Vienna da ya cosh e phone number get 7 
English : Danny I do not care, rather insult Vienna. Her phone number contains number 7

(part of the data deleted here because it contained insults)

\section{Participant 4: Harold}

CPE: Vienna gerrrrrat! Na me cosh you?

English: Vienna go away! I'm I the one who insulted you?

\section{Participant 5: Vienna}

CPE: $\quad$ Harold i c say my name too sweet for ur mop you and Zui

English: Harold I see that you like my name, just like Zui.

\section{Participant 4: Harold}

CPE: Hahahaha ... ha you do sabi eh?

English: Hahahaha... How do you know that? (Rhetorical question)

\section{Participant 5: Vienna}

\section{CPE: $\quad$ D man shift! I no get ya time D sharp}

English: $\quad$ Go away this guy! I do not have time for you this morning

\section{Participant 6: Ayuk}

CPE: $\quad$ Mornx Danny ... ha you nnang?

English: Good Morning Danny LLA ... How did you sleep?

In addition to the above, we can also observe the copious use of CPE from another group of Cameroonians known as Cameroon Pidgin English Journalist, when one of its members posted this information. In the second image, a woman can be seen holding a book incorrectly and the members of the group joke about it in CPE. Comments in CPE are in italics and they are followed by their translation.

\section{Poster- Solomon:}

CPE: From the way wey Mama Sarah handle dis book, you sure say ei di understand or ei di undershidon?

English: Form the way Mama Sarah is handling this book, do you think she understands it content or not?

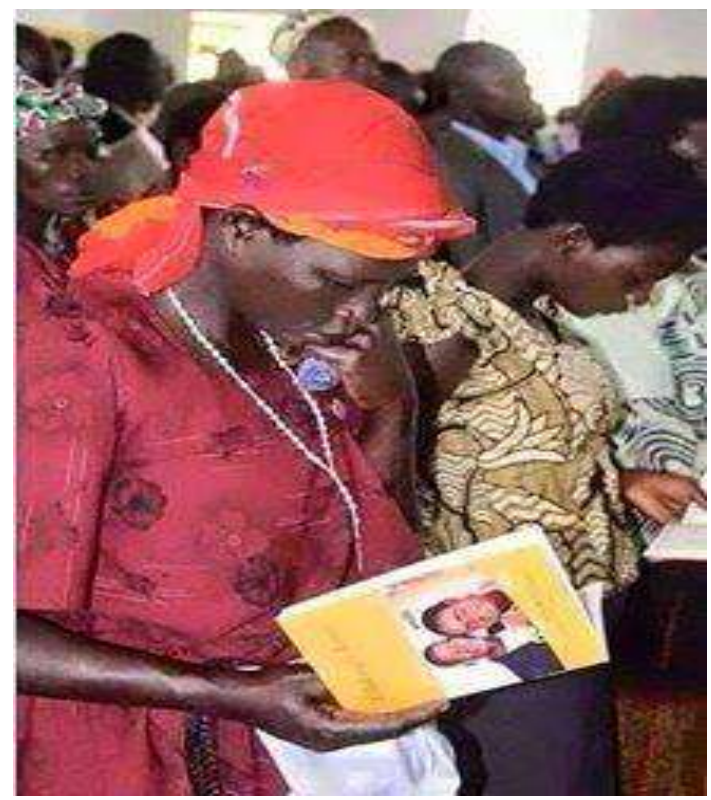

Image 2. Woman holding a book the wrong way

\section{Participant 1- Loiusa:}

CPE: $\quad$ new in town!!! illiterate school mistress

English: $\quad$ New in town!!! Illiterate school mistress

\section{Participant 2- Fredrick:}

CPE Solo na so e di take 4 understand well, na e style

English: Solomon! That is what she does to understand well. It is her style.

\section{Participant 3- Angel:}

CPE: $\quad$ mama sarah go for before na onley you sabi

English Mama Sarah, forge ahead. You are the only person who knows.

\section{Participant 4- Takang:}


CPE: $\quad y$ wona no fit think say de back cover dey upside down

English Why can you all not think that it is only the book cover that was wrongly placed?

Participant 5- Eric:

CPE: $\quad$ Solomon, ei di understand well well u no di see ei face

English Solomon, she can understand it. Don't you see her face?

\section{Participant 6- Ebot:}

CPE: $\quad$ lol na ei own way 4 read...even qlcveofzkhc...mama sarah di turnam read dam

English: $\quad$ Lol, it is her way to read, even if it were glcveofzkhc, Mama Sarah will turn it around and read it.

$\mathrm{CPE}$ does not require formal education and as it is acquired at a tender age many are highly proficient in this language, hence the preferential edge it has. Anglophone Cameroonians tend to acquire the languages they speak in slightly the same order: they first pick up one (or several) indigenous language and CPE at home, then a version of the English language in formal education and much later French. This pattern is fairly modified in most urban centers, where CPE tends to precede the indigenous language(s). Many researchers of Cameroon English have reported that the language enjoys unrivalled prestige as the language of international relations, technology, commerce, education, religion but not humour. A reduced proficiency in a language could mean that jokes may at least sometimes be experienced as less humourous. Language processing difficulties could interfere with the elements that are fundamental to humour. Even if a joke is understood, the meaning of the joke is obtained, timing delays can interfere with the humour experience. Derks et al (1997) have used eventrelated potentials and timing characteristics of the joke processing to argue that joke processing draws on fast-acting, automated skills.

Cameroonians in the fora above form part of a community, a community that shares thoughts and experiences in a familiar language, one that does not deepen their lows or prevent them from adequately expressing their highs. With CPE there is no regard for grammar or pronunciation. This eliminates every ounce of nervousness from any member who would like to participant in the humour of the day. The lack of consideration for grammar in writing as seen in the extract above reveals CPE as a not only easier-to-use language vis-à-vis other languages at the disposal of these Cameroonians (including English) but also an inclusive language; one which inhibits a hierarchical consideration of individuals. According to Nilsen, (2018), humour is used to strengthen ties and not to weaken them; humour should be used to empower. As such, CPE the friendly language, common to all participant seem to be the best choice for these jokes.

$\mathrm{CPE}$ is indispensable in order to navigate through multilingual and multicultural challenges in Cameroon. Anglophone Cameroonians of different ethnic groups need to commune and bond amidst these many languages. CPE allows them the unique opportunity to converse with profound intensity and intimacy and above all as a unit. The two social groups presented above, exhibit an abundant use of CPE although there is code-mixing between CPE and other languages such as English and other Cameroonian native languages. This flexibility is in fact what makes CPE an easier choice. Nkengasong, (2016) maintains that "[CPE] has drawn from multilinguistic and multicultural ecology to become a lingua franca as well as a formidable unifying factor for Cameroon's multilingual and multiethnic society because of its ethnic neutrality" (Nkengasong, 2016:1). This is echoed by Neba et al (2006) who assert that CPE belongs to no ethnic group and Mbufong who affirms that "[CPE] is the only language [in the country] that is not associated with a particular tribe, religion or with a specific colonial government." (Mbufong, 2013:474). It could thus be concluded that it is rather co-owned by all ethnic groups in the country. CPE in this line of thought allows for linguistic tolerance and therefore communication across the myriad of ethnic groups that exist in Cameroon. Linguistic tolerance is increasingly imperative in Cameroon nowadays as people's linguistic background is increasingly becoming a matter of contention. This study holds that with CPE, Cameroonians in the diaspora are not pressured to give up their individual linguistic heritage in order to adopt another's. This linguistics tolerance is crucial for the mental wellbeing of all members of these groups whose primary objective is entertainment.

Aside fostering linguistics tolerance, CPE serves as a language of amity, shared aims, commonality and of communion to these Cameroonians of diverse tribes overseas together with those in Cameroon. CPE is an integral part of Cameroon's culture, it constitutes Cameroon's pre- and post-colonial experiences, and according to Nkengasong (2016), it is a language with a history at national and international levels. Mbufong (2013) adds to this as he asserts that "[CPE] is the only language which expresses Cameroonian reality." Anglophone Cameroonians recount vividly their challenges, celebrate their victories, express their highs and lows effortlessly and with exactitude, through an unfussy and plain language which says little about a speaker's education, since CPE is not formally learned in school. Worthy of note is the fact that although CPE can betray one's background, that is ultimately a choice. Everyone can use a rural variety which is understood by all. CPE thus has the attribute value 'neutral socioeconomic status' (Myers-Scotton, 1976). CPE brings these individuals together, enables them express togetherness and reminds them of the cultural background which their share.

Di Carlo (2012) argues that a deliberate choice of a particular language indicates a deliberate choice of a particular way of entering the world and a particular way of sustaining relationships with those we come in contact with. It is language that creates room for people to share history, values, beliefs and ways of life. 


\section{CPE for individuals in Lower Fungom}

Linguistic heterogeneity has become the rule rather than the exception in many societies especially African societies including its rural parts. The people from Lower Fungom exhibit a unique scenery of linguistic and ethnic diversity. According to Di Carlo and Good (2014), Lower Fungom is one of the most linguistically diverse parts of the Cameroonian Grassfields. Lüpke (2016) goes further in saying that this area is one of the most linguistically diverse regions in the world with patterns of multilingualism that predate the emergence of Pidgins and Creoles and colonization. It is located in the Menchum Division, North West region of the country and it is an area of approximately 240 square kilometers in size, Di Carlo and Pizziolo (2012) hold that it is about the size of a city like Amsterdam. Lower Fungom comprises thirteen villages each with its own language named after the corresponding village. These villages are: Abar, Buu, Missong, Mashi, Mundabli, Munken, Mufu, Kung, Biya, Koshin, Fang, Ajumbu and Ngun. According to the perception of the locals, each village has its own language. However, Di Carlo (2016) affirms that there are at least eight distinct languages in this locality. This linguistic diversity, he asserts, yields a ratio of one language per $30 \mathrm{sq} \mathrm{km}$. With the exception of Fang and Koshin, all the region's languages are spoken by less than 1000 people. Some villages like Buu and Biya have about 200 and 100 inhabitants. Worthy of note, although some of its villages are quite small, each of the languages of Lower Fungom appears to be relatively vital. Children born and raised in its villages generally still speak the language associated with their home village through and through. Essene Agwara, (2013) avows that there are no monolingual speakers at least in adults; at the very least, people speak one local language plus CPE. This was corroborated by Ojong Diba (2019) whose study made use of recorded natural speech of multilinguals in Lower Fungom. The prevalent and intense linguistically and ethnically diverse scenario in Lower Fungom provides an exceptional opportunity to explore and highlight the use of a language of wider communication.

CPE is the mediating language in Lower Fungom; it is not known by all and sundry but it is becoming more and more popular in this region. Worthy of note, it is not a celebrated or prestigious language in this locality. Ideally, it is meant to be used with strangers exclusively or when in dire need. Inhabitants of these thirteen villages are incredibly multilingual. If individual A meets individual B and there is need for a conversation, if there is no mutual understanding of their primary native tongue, these inhabitants are most likely to use any of the other local languages in their repertoire rather than resort to CPE. As such even if five individuals from five different villages of Lower Fungom meet, they are most likely to hold a conversation as a group in the local languages of the area and not in CPE (Ojong Diba, 2019). This is the case in the excerpt below that was recorded in the course of a memorial service in Lower Fungom. The deceased was a mother who originated from Mufu but married and lived in Buu. The service in her honour was attended by the Fon of Buu and many other notables and indigenes from all over Lower Fungom. The excerpt shows that the Fon of Buu addresses the entire crowd in Buu 95 percent of the time in Missong (where his wife originates) 2 percent and CPE 3 percent of the time and this too at the very end of his address.

The excerpt below is divided into four parts; the except began with expressions from an elite of Buu village - the Nahtum. Nahtum is the woman in Buu who bathes the Fon and anoints him with special camwood on the days leading to his coronation right up to the day of his coronation. Because of this she is the only one who can physically touch the Fon. She opened the occasion in her native language Buu. She addressed the Fon of Buu as well as the entire crowd gathered in a compound for the occasion.

The remaining three parts were utterances from the Fon of Buu addressing the entire crowd.Utterances in Buu language are in Italics, those in Missong are in bold while those in CPE are in bold and underlined.

\section{Part one}

Transcription

English Free Translation

Transcription

English Free Translation

Language

Transcription

English Free Translation

\section{Part 2}

Transcription

English Free Translation me niomne bin fita

My children good afternoon

te fita oh

Yes, afternoon (crowd's response)

Buu

nfa yoyne kesine bin na bintsu dzen ne wahna woune be yeka bin dzomna kəfaba nawona na wouka piya

I thank you all who have come to congregate with your brother, to celebrate the death of your mother

ke Buu, ke Buu, ke Buu

Buu village! Buu village! Buu village!

Transcription mbe futfa ntie why mbe yen ka bu yafa kou bu adakeh no gbe nawu saka ka nogbi nayefa bge oude wayka fay gbina wudifey wusa na ka yewoude bubeh weyke bu fay nubəna təkə lehka fakou bier alabi tehlehkə ten nuebə na təkə lehk fakoubieh tedehna titəfe kam meobeh keke ya meh teda tite fa bibeh ta deta betifa kana keh kida kasa bisa yie beh 
English Free Translation

\section{Part 3}

Transcription

English Free Translation

Part 4

English Free Translation
I have called it three times for a reason. If you go these days to the village you will not see anybody to rule the village nor anybody pour drinks and give. So, anybody who is here thinking that this is not the village is wrong; this is Buu village. What we were doing in the village, is still what we are doing here. The tradition will not end with us, even our children will not abandon the tradition.

bidzoun bi lela

Is any one from Missong here?

As we be di talk for contri tok, any man way e no be di hear, I want make am say make $\mathrm{e}$ hear thing way we be di talk. I don talk say I no want violence ....

The Fon of Buu uses the local languages of Lower Fungom to address indigenes of Lower Fungom. As the Fon of Buu, it is almost a crime for him to use CPE to address his village members and even inhabitants of other villages of Lower Fungom as he is supposed to uphold the culture of Buu to the highest extent. He turned to CPE as a necessity only when he came into contact with the chief of the lone health center of Lower Fungom who originated form Esu and was consequently a stranger in Lower Fungom. Throughout the occasion and as tradition demands, the Fon of Buu served palm wine to some distinguished members of Lower Fungom according to villages and quarters. He summoned them using the languages of Lower Fungom. When he was done with indigenes of Lower Fungom, he began serving strangers, the first of them was the chief of center of the health unit in Lower Fungom. It is with him that the Fon used CPE for the first time in the recording.

Todd (1984) defines a pidgin as a marginal language that arises to fulfill certain restricted communication needs among people who have no common language. CPE is certainly no longer a marginal language especially if it implies 'insufficiency' or 'negligible'. CPE was not even in Lower Fungom till the late 1960s, but if it can be used today to address a crowd then its 'margins' have spread significantly. Also, the excerpt reveals that CPE does more than play a restricted communication need, it most certainly fulfills a dire communication need in this instance in Lower Fungom but not a narrowed or restricted one. As standard English is learned formally in schools, non-educated people who constitute rural areas such as Lower Fungom, are left with CPE for out-group communications. So, in Lower Fungom, CPE plays an indispensable communicative function; it establishes a communication cord between people of Lower Fungom and strangers. It allows these people famed for their linguistic diversity to communicate beyond their geographical boundaries.

Moreover, many individuals come into this region for diverse purposes. Lower Fungom had just one market day, this meant that people from all the thirteen villages of Lower Fungom met in this market. Others who came to do business from neighbouring villages outside Lower Fungom also met in the same market. The government school teachers, pastors and priests were all strangers in Lower Fungom and so where their doctor and medical personnel. CPE was thus used in Lower Fungom in the market square with traders from other parts of the North West such as neighbouring villages of Weh and Esu. In the same light, CPE is also used in churches by pastors and priests as they were only sent there for missionary purposes. The pastor of the Presbyterian Church in Cameroon (PCC) who is in charge of Abar, Buu and Munkeng was from Wum, a neighbouring village and spoke aghem while the pastor of the Cameroon Baptist Convention (CBC) Abar was from Nkambe, a city at the north edge of the Bamenda Grassfields . All thirteen villages only have one health center; it is located in Abarthe centre village of the area. The chief of center did not speak any of the languages of this area as he was from Esu. Consequently, in churches, in the health center and in the market square where there are diverse group of people, CPE was used. Native languages were used among indigenes of the area, but with strangers, CPE did the job.

Data for this study demonstrates that in using CPE attention is not paid to pronunciation, grammar or orthography. Neba et al (2006) echo this thought as they believe that CPE can be used efficiently by all and sundry. Someone from the most rural area can conveniently discuss with someone from the best urban area. Another from the highest social status can conveniently use CPE with someone who has never had any formal education. Its ethnic neutrality status is a bonus to Anglophone Cameroonians who use this language. For CPE to predictably betray one's proficiency in standard English, ethnicity or socio-economic status, would be the deliberate choice of its user. CPE thus possesses the propensity to deemphasize linguistic, ethnic and socio-economic boundaries. Mbangwana (1983) emphasized the importance of CPE in Cameroon asserting that it was indispensable to Cameroonians irrespective of their educational status or their linguistic background. He declared that:

Pidgin English is very crucial as a communication bridge.... It links an anglophone to another Anglophone, an educated Cameroonian to another educated one, a non-educated Cameroonian to another non-educated one, and more importantly, an educated Cameroonian to a non-educated one. (P. 87)

In an investigation on the ideologies and attitudes of Cameroonians towards CPE, Abongdia (2014)'s respondents revealed they felt free when using CPE. Her respondents also believed that CPE was a language that breeds familiarity and assurance among Cameroonians. As a matter of fact, Abongdia (2014) opines that overseas, when people meet and are introduces as Anglophone Cameroonians, there is an immediate switch to CPE and the moment one of them fails to respond in this language, a feeling of doubt, aloofness and uneasiness is automatically born. 


\section{Conclusion}

This language which historically started in Cameroon in 1472 when the coastal inhabitants of Cameroon first had contact with European explorers has stretched in a startling manner. In its oral form and by its relationship with the two official languages of the country, CPE is simpler. In its written form, it is equally simpler especially because it does not have a standardized form. It is a language well-suited for humour among people who share a common heritage, whether they are highly educated or not. It is also a language that comes in terribly handy in a remote rural region, inhabited by individuals who have not been through formal education, where standard English or French is learned. It is thus a language that the country desperately needs to deal with its linguistic diversity. Worthy of note, CPE itself has refused to die; with everything that has been thrown at it, the language continues to show fortitude. This study presents CPE as not just an ordinary, contemporaneous, unexceptional, common code; it is both historic and phenomenal. This language to Anglophone Cameroonians embodies their history, displays their identity, it expresses freedom, solidarity and affection. CPE may not be a language that sparks elegance, its origin could be said to be contemptuous but data for this study reveals that it is an indispensable tool for communication to Cameroonians at large. It is a language that has grown by leaps and bounds and is here to stay.

\section{References}

Abongdia, J. F. A. (2014). Ideologies and attitudes towards Pidgin English in Cameroon. Mediterranean Journal of Social Sciences, 5(7), 601.

Achimbe, Eric A. (2007). Anglophonism and Francophonism: The Stakes of (official) Language identity in Cameroon. Alizes: Revue angliciste de la reunion 25/26, 7-26.

Atechi, S. (2011). Cameroon and Pidgin English. Journal of Applied Linguistics, December 2011

Chiatoh, B. A. A. (2014). The Cameroonian experience in mother tongue education planning: the community response framework. Current Issues in Language Planning, 15(4), 376-392.

Derks, D., Fischer, A. H., \& Bos, A. E. (2008). The role of emotion in computer-mediated communication: A review. Computers in Human Behavior, 24(3), 766-785.

Di Carlo, P. (2012). Lower Fungom linguistic diversity and its historical development; Proposals from a multidisciplinary perspective. Africana Linguistica. 17, 53-100.

Di Carlo, P \& Good, J. (2014). What are we trying to preserve? Diversity, change, and ideology at the edge of the Cameroonian Grassfields. In P. Austin \& J. Sallabank (Eds.). Endangered languages: Beliefs and ideologies in language documentation. Oxford and New York: Oxford University Press. 229-262

Di Carlo, P. \& Pizziolo, G. (2012). Spatial reasoning and GIS in linguistic prehistory. Two case studies from Lower Fungom (North West Cameroon). Language dynamics and change, 2(2), 150-183.

Di Carlo, P. (2016). Multilingualism, affiliation and spiritual insecurity. From phenomena to processes in language documentation. In M. Seyfeddinipur (Ed.). African language documentation new data, methods and approaches. Language documentation \& conservation special publication 10:71-104.

Echu, G. (2003). Coping with multilingualism: Trends in the evolution of language policy in Cameroon. PhiN, $25,31-46$.

Eberhard, D. M., Gary, F. S. \& Fennig, C. D. (eds.). (2020). Ethnologue: Languages of the World. Dallas, Texas: SIL International.

Essene Agwara, Angiachi. (2013). Rural multilingualism in the north west region of Cameroon. (Unpublished MA thesis). University of Buea, Cameroon.

Lüpke, F. (2016). Uncovering small-Scale multilingualism. Critical Multilingualism Studies 4(2), 35-74.

Mbangwana, P. (1983). The Scope and the Role of Pidgin English in Cameroon. In Koenig E. L., Chia, E. \& Povey, J. (eds.) A Sociolinguistic Profile of Urban Centres in Cameroon. Los angeles: Crossroads Press. 79-92.

Mbufong, P. (2013). The Cameroonization of English. US-China Foreign Language, 11(6), 475-482.

Myers-Scotton, C. (1976). Strategies of neutrality: Language choice in uncertain situations. Language, 52(4), 919-941.

Neba., A. N, Chibaka, E. F. \& Atindogbe, G. G. (2006). Cameroon Pidgin English (CPE) as a tool for Empowerment and National Development. African Study Monograpgh, 27(2), 39-61.

Nkengasong, N. (2016). A Grammar of Cameroonian Pidgin. Cambridge scholars Publishing.

Nilsen, D. L., \& Nilsen, A. P. (2018). The language of humor: An introduction. Cambridge University Press.

Ojong, D. R. (2019). The Sociolinguistic Dynamics of Rural Multilingualism in Africa. The Case of Lower Fungom. (Unpublished) $\mathrm{PhD}$ thesis. University of Buea. Cameroon.

Todd, L. (1990). Pidgins and Creoles. New edition. Routledge \& Kegan Paul, London.

Todd, L. (1984). Modern Englishes: Pidgins and Creoles. Oxford: Blackwell

Worldometers.info. (2020). Elaboration of data by United Nations, Department of Economic and Social Affairs, Population Division. www.worldometers.info. 